\title{
Haloperidol is as effective as ondansetron for preventing postoperative nausea and vomiting
}

\author{
[L'balopéridol est aussi efficace que l'ondansétron dans la prévention des nausées \\ et vomissements postopératoires]
}

Yi Lee MD, ${ }^{*}$ Po K. Wang MD, ${ }^{*}$ Hsien Y. Lai PhD, ${ }^{*}$ Yao L. Yang MD, ${ }^{*}$ Chin C. Chu MD, $†$ Jhi J. Wang PhD†

\begin{abstract}
Purpose: Recent warnings regarding the safety of droperidol have limited use of this drug as an antiemetic. Haloperidol, a butyrophenone derivative similar to droperidol, has not been rigorously evaluated as an antiemetic. The aim of this study was to compare the prophylactic antiemetic efficacy of haloperidol vs ondansetron for the prevention of postoperative nausea and vomiting (PONV) after general anesthesia.
\end{abstract}

Methods: Ninety non-smoking female patients were eligible to participate in this randomized double-blinded study. Approximately $30 \mathrm{~min}$ before the end of surgery, patients were randomly assigned to receive either haloperidol $2 \mathrm{mg}$ iv, or ondansetron $4 \mathrm{mg}$ iv, respectively. The incidence of PONV, average pain and sedation scores, recovery times, and changes of the rate-corrected QT (QTc) interval were observed postoperatively.

Results: The proportion of patients who experienced PONV in the first $24 \mathrm{hr}$ was similar in the two groups (28\% and $26 \%$ for haloperidol and ondansetron groups, respectively). The incidence of PONV was significantly less in both groups than predicted according to the patients' underlying risks (53\% for the haloperidol group, $P=0.016 ; 51 \%$ for the ondansetron group, $P=0.015)$. Pain scores, sedation scores, and recovery times were similar in the two groups, and no prolongation of the QTc interval was observed in either group.

Conclusions: Haloperidol $2 \mathrm{mg}$ iv given 30 min before the end of surgery is effective in preventing PONV, with efficacy comparable to ondansetron $4 \mathrm{mg}$ iv for the first $24 \mathrm{hr}$ after general anesthesia.

CAN J ANESTH $2007 / 54: 5 /$ pp 349-354
Objectif : De récentes mises en garde quant à l'innocuité du dropéridol ont limité l'utilisation de ce médicament comme antiémétique. L'halopéridol, un dérivé du butyrophénone similaire au dropéridol, n'a pas été évalué rigoureusement en tant qu'antiémétique. L'objectif de cette étude était de comparer l'efficacité antiémétique prophylactique de l'halopéridol vs l'ondansétron dans la prévention des nausées et vomissements postopératoires (PONV) après une anesthésie générale.

Méthode : Quatre-vingt-dix patientes non fumeuses satisfaisaient aux conditions de participation à cette étude randomisée à double insu. Environ 30 min avant la fin de la chirurgie, les patientes ont été randomisées à recevoir respectivement soit $2 \mathrm{mg}$ iv d'halopéridol, soit $4 \mathrm{mg}$ iv d'ondansétron. Après l'opération, l'incidence de PONV, les moyennes des scores de douleur et de sédation, les temps de rétablissement et les changements de l'intervalle $Q T$ à taux corrigé (QTC) ont été observés.

Résultats : La proportion de patientes souffrant de PONV dans les premières 24 h était semblable dans les deux groupes (28\% et $26 \%$ pour les groupes halopéridol et ondansétron respectivement). L'incidence de PONV était significativement plus basse que prévue dans les deux groupes en considérant les risques préopératoires sous-jacents des patientes (53\% pour le groupe halopéridol, $P=$ 0,$016 ; 51 \%$ pour le groupe ondansétron, $P=0,015$ ). Les scores de douleur et de sédation, ainsi que les temps de rétablissement étaient similaires dans les deux groupes, et aucune prolongation de l'intervalle QTc n'a été observée dans l'un ou l'autre groupe.

Conclusion : L'halopéridol $2 \mathrm{mg}$ iv administré 30 min avant la fin de la chirurgie est efficace dans la prévention de PONV, et présente une efficacité comparable à l'ondansétron $4 \mathrm{mg}$ iv durant les premières $24 h$ après une anesthésie générale.

From the Department of Anesthesiology, ${ }^{*}$ Buddhist Tzu-Chi Medical Center, Tzu-Chi University School of Medicine, Hualien; and the Departments of Anesthesiology and Medical Research, $\dagger$ Chi-Mei Medical Center, Tainan, Taiwan, ROC.

Address correspondence to: Prof. Jhi-Joung Wang, Chairman, Department of Anesthesiology and Department of Medical Research, ChiMei Medical Center, Tainan County, Taiwan, No. 901, Chung-Hwa Road, Yung-Kang City, Tainan County, Taiwan.

E-mail: jjw400002@hotmail.com

Accepted for publication February 5, 2007.

Revision accepted February 15, 2007. 
$\mathrm{P}$ OSTOPERATIVE nausea and vomiting (PONV) are among the most unpleasant experiences following surgery performed under general anesthesia. ${ }^{1}$ Droperidol, a butyrophenone antiemetic, was commonly used as an antiemetic for PONV. ${ }^{2}$ However, on December 5, 2001, the U.S. Food and Drug Administration issued a "black box warning" suggesting that unexpected cardiovascular death could occur at normal therapeutic doses of droperidol. ${ }^{3}$ Of particular concern was the possibility of QT prolongation leading to torsades de pointes. ${ }^{4}$ Despite the argument of many clinicians that the warning was inappropriate, this announcement led to a marked withdrawal of droperidol from the market and search for a cost-effective alternative.

Haloperidol, a major tranquilizer (antipsychotic, neuroleptic) which has a chemical structure similar to that of droperidol, has been considered a possible substitute for droperidol. ${ }^{5}$ Haloperidol has been used commonly for treating schizophrenia and related psychoses. ${ }^{6}$ It has also been used in the treatment of chemotherapy-, radiotherapy-, and opioid-related nausea and vomiting. ${ }^{6}$ Recently, a meta-analysis reported that haloperidol was effective in the prevention of PONV, however, the supporting evidence was dated (1962 to 1972) and incomplete. Therefore, we conducted a double-blinded, randomized clinical trial to test the prophylactic antiemetic efficacy of haloperidol in comparison with ondansetron, a well established antiemetic agent, for the prevention of PONV after general anesthesia.

\section{Methods}

With institutional approval and the written informed consent of the patients, 90 ASA grade I and II female patients scheduled for gynecologic, urologic, thyroid, breast, or plastic surgeries were enrolled in this randomized, double-blinded study. Excluded were patients with obvious airway problems, obesity (body mass index $>25 \mathrm{~kg} \cdot \mathrm{m}^{-2}$ ), those who were pregnant, and those who had a chronic cough, psychiatric illness, or clinically significant major organ disease. Finally, anyone who had consumed an antiemetic medication within $24 \mathrm{hr}$ prior to commencing the study was excluded.

In the preoperative holding area, patients were allocated randomly to one of the two groups $(n=45$ for each group) using a computer-generated random number table. Approximately $30 \mathrm{~min}$ before the end of surgery, patients in the haloperidol group received haloperidol $2 \mathrm{mg} i v$; patients in the ondansetron group received ondansetron $4 \mathrm{mg} i \mathcal{~}$. Study drugs were prepared to equal volumes of $2 \mathrm{~mL}$ in identical labelled syringes by personnel blinded to the study protocol, and were administered in a double-blind fashion.

Anesthesia was standardized. Induction of anesthesia was achieved with fentanyl $2 \mu \mathrm{g} \cdot \mathrm{kg}^{-1}$ iv and propofol $3 \mathrm{mg} \cdot \mathrm{kg}^{-1}$ iv and tracheal intubation was facilitated by the administration of rocuronium 0.8 $\mathrm{mg} \cdot \mathrm{kg}^{-1}$ iv. Anesthesia was maintained with sevoflurane $2-5 \%$ (inspired concentrations) in oxygen. Ventilation was mechanically controlled, and adjusted to maintain end-tidal $\mathrm{CO}_{2}$ values between $35-45$ $\mathrm{mmHg}$ throughout surgery. Additional rocuronium was administered as required. All patients received ketorolac $30 \mathrm{mg}$ iv before the end of surgery to control postoperative pain. For reversal of residual neuromuscular block, a combination of glycopyrrolate $0.6 \mathrm{mg}$ and neostigmine $3 \mathrm{mg}$ was administered intravenously and the trachea was extubated when the patient was awake. No opioids were administered during the operation.

In accordance with previously published guidelines on the conduct of PONV studies, three postoperative time periods were evaluated: the 0-2, 2-24, and 0-24 hr following anesthesia. ${ }^{7}$ For the first two hours after anesthesia in the postanesthesia care unit (PACU), nausea score, episodes of vomiting, the presence or absence of nausea and vomiting, levels of pain and sedation experienced by patients, and adverse effects such as cardiac dysrhythmias, headache and extrapyramidal effects were recorded by a trained investigator without knowledge of which treatment the patients had received. The intensity of each nausea episode was graded as mild (discomfort noticed but no disruption of anticipated normal activity), moderate (discomfort sufficient to affect anticipated normal activity), or severe (inability to perform normal activity). A vomiting episode was defined as vomiting/retching events occurring in rapid sequence within a one-minute period. If the interval between two bouts of emesis exceeded one minute, they were considered separate episodes. If there were more than four episodes within the 24-hr observation period, the vomiting was considered severe. ${ }^{8}$ The rescue medication (metoclopramide $25 \mathrm{mg} i \mathrm{v}$ ) could be administered to any patient who experienced an episode of moderate or severe nausea, an episode of vomiting, or who requested rescue antiemetic medication. Twenty-four hours following discharge from the PACU, the cumulative incidence of nausea or/and vomiting and the rescue antiemetic utilization were recorded.

Postoperative pain intensity was rated by the patients using a $10-\mathrm{cm}$ visual analogue scale (VAS), with 0 symbolizing no pain and 10 the worst pain imaginable. When patients complained of excessive 
TABLE I Patient characteristics and variables related to PONV

\begin{tabular}{|c|c|c|c|}
\hline Group & $\begin{array}{l}\text { Haloperidol } \\
(n=43)\end{array}$ & $\begin{array}{l}\text { Ondansetron } \\
(n=43)\end{array}$ & $P$ \\
\hline Age $(\mathrm{yr}) ;$ mean $\pm \mathrm{SD}$ & $43 \pm 13$ & $40 \pm 13$ & 0.502 \\
\hline Weight $(\mathrm{kg})$; mean $\pm \mathrm{SD}$ & $58 \pm 5$ & $56 \pm 5$ & 0.228 \\
\hline History of PONV $n(\%)$ & $8(19)$ & $10(23)$ & 0.596 \\
\hline History of motion sickness $n(\%)$ & $20(47)$ & $17(40)$ & 0.514 \\
\hline $\begin{array}{l}\text { Duration of anesthesia }(\min ) \\
\text { mean } \pm \text { SD }\end{array}$ & $154 \pm 58$ & $138 \pm 73$ & 0.28 \\
\hline \multicolumn{4}{|l|}{ Surgical type } \\
\hline Gynecologic $n(\%)$ & $10(23)$ & $12(28)$ & 0.62 \\
\hline Urologic $n(\%)$ & $12(28)$ & $8(19)$ & 0.307 \\
\hline Breast $n(\%)$ & à8 (19) & $6(14)$ & 0.55 \\
\hline Thyroid $n(\%)$ & $8(19)$ & $10(23)$ & 0.59 \\
\hline Plastic $n(\%)$ & $5(12)$ & $7(16)$ & 0.53 \\
\hline Risk factors; mean $\pm S D$ & $2.7 \pm 0.5$ & $2.6 \pm 0.5$ & 0.323 \\
\hline Risk of PONV (\%); mean \pm SD & $54.7 \pm 9.5$ & $51.9 \pm 9.9$ & 0.503 \\
\hline \multicolumn{4}{|l|}{ Postoperative pain scores (VAS) } \\
\hline $0-2 \mathrm{hr} ;$ mean $\pm \mathrm{SD}$ & $3.2 \pm 0.9$ & $3.5 \pm 0.9$ & 0.113 \\
\hline $2-24 \mathrm{hr} ;$ mean $\pm S D$ & $2.4 \pm 0.9$ & $2.5 \pm 0.7$ & 0.79 \\
\hline
\end{tabular}

TABLE II Frequency of PONV and requirement for rescue antiemetics

\begin{tabular}{llll}
\hline Group & $\begin{array}{l}\text { Haloperidol } \\
(n=43)\end{array}$ & $\begin{array}{l}\text { Ondansetron } \\
(n=43)\end{array}$ & $P$ \\
\hline $0-2$ hr & $6(14)$ & $9(21)$ & 0.394 \\
Nausea only $n(\%)$ & $5(12)$ & $1(2)$ & 0.090 \\
Vomiting $n(\%)$ & $11(26)$ & $10(23)$ & 0.802 \\
Total PONV $n(\%)$ & $7(16)$ & $4(9)$ & 0.333 \\
Rescue antiemetics $n(\%)$ & & & \\
2-24 hr & $6(14)$ & $8(19)$ & 0.559 \\
Nausea only $n(\%)$ & $4(9)$ & $3(7)$ & 0.694 \\
Vomiting $n(\%)$ & $10(23)$ & $11(26)$ & 0.802 \\
Total PONV $n(\%)$ & $8(19)$ & $6(14)$ & 0.559 \\
Rescue antiemetics $n(\%)$ & & & \\
$0-24$ hr & $7(16)$ & $8(19)$ & 0.777 \\
Nausea only $n(\%)$ & $5(12)$ & $3(7)$ & 0.458 \\
Vomiting $n(\%)$ & $12(28)$ & $11(26)$ & 0.808 \\
Total PONV $n(\%)$ & $10(23)$ & $8(19)$ & 0.596 \\
Rescue antiemetics $n(\%)$ &
\end{tabular}

$\mathrm{PONV}=$ postoperative nausea and vomiting.

pain and requested analgesia, ketorolac $30 \mathrm{mg}$ iv every six hours was given. Sedation was assessed during the first $15,30,60,90$ and $120 \mathrm{~min}$ in the PACU using the five-point Observer's Assessment of Alertness/ Sedation $(\mathrm{OAA} / \mathrm{S})$ scale $($ where $\mathrm{l}=$ awake/alert and 5 = deep sleep). ${ }^{9}$ Recovery times from discontinuation of anesthesia until opening of the patient's eyes (awakening time), ability to follow commands (e.g., squeezing of the investigator's hand), and orientation to person or place, as well as the time to achieve a modified Aldrete score of 10 were recorded.

A 12-lead electrocardiogram was obtained before the operation. The standard electrocardiographic lead II was continuously monitored at a speed of 25 $\mathrm{mm} \cdot \mathrm{sec}^{-1}$ and amplification of $0.1 \mathrm{mV} \cdot \mathrm{mm}^{-1}$. Heart rate was calculated from three $\mathrm{R}-\mathrm{R}$ intervals preceding the measured QT intervals. The QT intervals were measured manually from the onset of the QRS complexes to the end of the $\mathrm{T}$ wave and corrected for the patient's heart rate using the formula of Bazett (QTc $\left.=\mathrm{QT} / \mathrm{R}-\mathrm{R}^{0.5}\right) .{ }^{10}$ The $\mathrm{QTc}$ interval was measured ten minutes after administration of the study medication.

Our primary goal was to compare the prophylactic antiemetic efficacy of haloperidol $v s$ ondansetron following general anesthesia. For ethical reasons there was no placebo group. Instead, the observed incidences were compared to the predicted incidences based upon Apfel' risk score. ${ }^{11}$ The primary efficacy endpoint was the incidence of PONV. The secondary endpoint was the safety of treatment.

Sample size was based upon Apfel' risk score, with an expected incidence of PONV in this study was in the region of $60 \% .{ }^{12}$ A $50 \%$ reduction in the incidence of PONV (from $60 \%$ to $30 \%$ ) in the treatment groups was considered to be clinically relevant. With an $\alpha$ error of 0.05 (two-sided) and a $\beta$ error of 0.2 (power $=0.8$ ), 43 patients were required in each group. Fortyfive patients per group would compensate for potential dropouts. Data were analyzed using Chi-squared analysis and Fisher's exact test (two sided). The 5\% level of probability $(P<0.05)$ was taken as significant. Commercial SPSS 10.0 software for Windows (SPSS Inc., Chicago, IL, USA) was used for the analysis.

\section{Results}

Ninety patients were screened, and of the 90 patients enrolled in the study, four were later withdrawn for incomplete data collection. The remaining 86 completed the protocol. Patient characteristics, duration of anesthesia, surgical types, the risk factors for PONV ${ }^{11}$ estimated risk of PONV ${ }^{12}$ and postoperative pain scores (VAS) at the three different time intervals were similar in the two groups (Table I).

Patients in both groups reported a low incidence of PONV $(\leq 30 \%)$ within $24 \mathrm{hr}$ postoperatively. No significant difference was found between groups with respect to the following variables: the incidences of nausea, vomiting, total PONV, and use of rescue antiemetics during the periods $0-2,2-24$, and $0-24 \mathrm{hr}$ postoperatively (Table II). In addition, the observed incidences of $24 \mathrm{hr}$ PONV in both groups were significantly less than the predicted incidences $(53 \%$ for 
TABLE III Predicted and observed incidence of postoperative nausea and vomiting

\begin{tabular}{lll}
\hline Group & $\begin{array}{l}\text { Haloperidol } \\
(n=43)\end{array}$ & $\begin{array}{l}\text { Ondansetron } \\
(n=43)\end{array}$ \\
\hline Predicted incidence $n(\%)$ & $23(53)$ & $22(51)$ \\
Observed incidence $n(\%)$ & $12(28)$ & $11(26)$ \\
$P$ & 0.016 & 0.015 \\
\hline
\end{tabular}

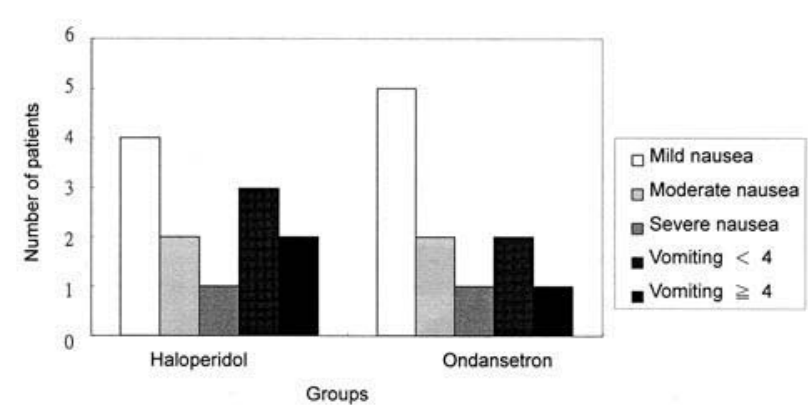

FIGURE Number of patients in mild, moderate and severe nausea categories and vomiting episodes during the first $24 \mathrm{hr}$ postoperatively.

haloperidol group, $P=0.016 ; 51 \%$ for ondansetron group, $P=0.015$; Table III). Also, the severities of nausea and vomiting were similar between groups (Figure). Mean sedation levels and times to awakening were also similar in the two groups (Table IV). No patient experienced headache or extrapyramidal symptoms.

The QTc intervals before administration of study medications were similar in both groups (haloperidol group: $423.85 \pm 19.37 \mathrm{msec}$, ondansetron group: $423.33 \pm 15.76 \mathrm{msec} ; P=0.892)$. Ten minutes after administration of the study medication, the QTc intervals were not different between groups (haloperidol group: $427.38 \pm 12.43 \mathrm{msec}$, ondansetron group: $428.05 \pm 15.29 \mathrm{msec} ; P=0.827)$. No patient in either group had a QTc value $>470 \mathrm{msec}$, and no cardiac dysrhythmias were observed.

\section{Discussion}

Ondansetron $4 \mathrm{mg}$ iv administered immediately before the end of surgery has established efficacy in preventing PONV. ${ }^{13}$ In this double-blind, randomized clinical trial, we found that haloperidol $2 \mathrm{mg}$ in administered before the end of surgery produced
TABLE IV Sedation scores and recovery times in the postanesthesia care unit

\begin{tabular}{llll}
\hline Group & $\begin{array}{l}\text { Haloperidol } \\
(n=43)\end{array}$ & $\begin{array}{l}\text { Ondansetron } \\
(n=43)\end{array}$ & $P$ \\
\hline Sedation scores & & & \\
At $15 \mathrm{~min}$ & $2.1 \pm 0.6$ & $1.9 \pm 0.7$ & 0.199 \\
At $30 \mathrm{~min}$ & $1.7 \pm 0.7$ & $1.6 \pm 0.7$ & 0.518 \\
At $60 \mathrm{~min}$ & $1.3 \pm 0.6$ & $1.3 \pm 0.5$ & 0.839 \\
At $90 \mathrm{~min}$ & $1.1 \pm 0.4$ & $1.2 \pm 0.4$ & 0.564 \\
At $120 \mathrm{~min}$ & $1.1 \pm 0.3$ & $1.1 \pm 0.4$ & 0.506 \\
Recovery times (min) & & & \\
Awakening & $6.6 \pm 2.1$ & $6.1 \pm 2.2$ & 0.311 \\
Obey to comments & $8.5 \pm 2.2$ & $7.8 \pm 1.9$ & 0.157 \\
Orientation & $11.7 \pm 2.8$ & $11.3 \pm 2.7$ & 0.531 \\
Aldrete 10 & $20.8 \pm 3.3$ & $20.1 \pm 3.5$ & 0.339 \\
\hline Drta prente
\end{tabular}

Data presented as means \pm SD.

a prophylactic antiemetic effect on PONV similar to that of ondansetron $4 \mathrm{mg}$.

For antiemetic purposes, the dose of haloperidol is much lower than that required for use as an antipsychotic. ${ }^{5}$ A meta-analysis suggested that haloperidol 0.5 to $4 \mathrm{mg}$ is more efficacious than placebo, but a dose-response could not be established within that dose range. ${ }^{5}$ The authors suggested that parental single doses between $\mathrm{l}$ and $2 \mathrm{mg}$ are efficacious, with minimal toxicity, for the prevention of PONV. In a previous study, haloperidol $2 \mathrm{mg}$ iv was used in patients undergoing orthopedic or endoscopic urologic procedures to prevent intrathecal morphinerelated PONV. ${ }^{14}$ However, the incidence of PONV was relatively high ( $55 \%$ frequency). In a more recent study, haloperidol $1 \mathrm{mg}$ iv proved to be an effective antiemetic for the early ( $0-2 \mathrm{hr}$ ) prevention of nausea and vomiting. ${ }^{15}$ Yet, the overall $24 \mathrm{hr}$ incidence of PONV (41\%) did not improve compared with placebo (56\% incidence ). In these studies, study medications were administered at the start of anesthesia. However, droperidol is most effective when administered at the end of surgery. ${ }^{16,17}$ Given that haloperidol is pharmacologically similar to droperidol for the control of nausea and vomiting, and the time to peak plasma concentration from $i v$ injection is only five to $15 \mathrm{~min},{ }^{6}$ it seemed logical that haloperidol might be more effective when administered at the end of surgery, thereby producing a more sustained antiemetic effect in the postoperative period. In our study, a higher dose of haloperidol $(2 \mathrm{mg}$ ) was given $30 \mathrm{~min}$ before the anticipated end of surgery, resulting in a $24 \mathrm{hr}$ incidence of PONV that is only $28 \%$ for an at-risk population. Whether a higher dose, or administering 
haloperidol at the end of surgery will increase the antiemetic efficacy warrants further investigation.

A concern regarding haloperidol is its potential to cause sedation, and in rare instances, extrapyramidal symptoms. ${ }^{5}$ However, sedation is a rare adverse event and many clinicians consider the drug to be nonsedating. ${ }^{6}$ In this study, haloperidol $2 \mathrm{mg}$ was associated with a low level of sedation which was similar to that of ondansetron $4 \mathrm{mg}$. No extrapyramidal symptoms were reported.

Based upon the Apfel' risk score for PONV, ${ }^{11}$ all patients had either two or three risk factors (female, non-smoking, history of motion sickness or previous PONV). The expected risks for PONV were 40 to $60 \%$. Since this simplified risk score has been validated, and the study medications are already known to be effective for PONV, it was considered not ethically justified to exclude high risk patients prophylactic treatment against PONV. Therefore, we did not include a placebo group in the study design. Instead, observed incidences were compared to predicted incidences in both treatment groups based upon the risk score. The results showed that $26 \%$ of patients in the ondansetron group reported PONV in the first 24 hr postoperatively, which was significantly less than predicted according to the patients' underlying risks (51\%). In addition, haloperidol showed similar efficacy to ondansetron for this indication.

Previous prospective investigations have shown that the different incidences of PONV are associated more with individual PONV risk factors and less by the operation itself. ${ }^{18}$ Furthermore, study designs that analyze only one type of surgery have already been criticized. ${ }^{7}$ Therefore, we used Apfel's simplified risk score instead of selecting patients undergoing just one type of surgery. In our study, the type of surgery and the number of risk factors were found to be similar between groups (Table I). We believe that the study results are directly related to the study medications.

Previous studies have suggested that high dose haloperidol may cause QTc prolongation. ${ }^{19,20}$ In a meta-analysis, 1,397 patients received different regimens of haloperidol, however, there were no reports of cardiac dysrhythmias. $\left.{ }^{5} 5-\mathrm{HT}_{3}\right]$ are also known to prolong the QTc interval at high dosages. ${ }^{21}$ Several cases of cardiac dysrhythmias after administration of ondansetron have been reported. ${ }^{22,23}$ In the current study, the QTc interval was not significantly different between groups ten minutes after administration of the study medication, and there was no evidence of any adverse effect on cardiac rhythm. According to sex-related thresholds (QTc $>470 \mathrm{msec}$ in women), ${ }^{24}$ no prolonged QTc interval was found in any patient.
The use of ondansetron as a first line antiemetic has been criticized because of its high cost. ${ }^{25}$ Our hospital pharmacy's acquisition cost for a 4-mg ampoule of ondansetron is Can \$26.9, whereas, a $2-\mathrm{mg}$ of haloperidol is Can $\$ 0.41$.

In conclusion, the prophylactic iv administration of haloperidol $2 \mathrm{mg} 30 \mathrm{~min}$ before the anticipated end of surgery effectively reduces the incidence of PONV without any adverse effect on cardiac rhythm. Treatment using ondansetron, a relatively more costly $5-\mathrm{HT}_{3}$ antagonist, did not provide superior benefit compared to haloperidol in the present study.

\section{References}

1 Myles PS, Williams DL, Hendrata M, Anderson H, Weeks $A M$. Patient satisfaction after anaesthesia and surgery: results of a prospective survey of 10,811 patients. Br J Anaesth 2000; 84: 6-10.

2 Tramer MR. A rational approach to the control of postoperative nausea and vomiting: evidence from systemic reviews. Part II. Recommendations for prevention and treatment, and research agenda. Acta Anaesthesiol Scand 2001; 45: 14-9.

3 Gan TJ, White PF, Scuderi PE, Watcha MF, Kovac A. FDA "black box" warning regarding use of droperidol for postoperative nausea and vomiting: is it justified? Anesthesiology 2002; 97: 287.

4 Mullins M, Van Zwieten R, Blunt JR. Unexpected cardiovascular deaths are rare with therapeutic doses of droperidol. Am J Emerg Med 2004; 22: 27-8.

5 Buttner $M$, Walder B, von Elm E, Tramer MR. Is lowdose haloperidol a useful antiemetic? A meta-analysis of published and unpublished randomized trials. Anesthesiology 2004; 101: 1454-63.

6 Vella-Brincat J, Macleod AD. Haloperidol in palliative care. Palliat Med 2004; 18: 195-201.

7 Apfel CC, Roewer N, Korttila K. How to study postoperative nausea and vomiting. Acta Anaesthesiol Scand 2002; 46: 921-8.

8 Wang JJ, Ho ST, Lee SC, Lin YC, Ho CMl. The use of dexamethasone for preventing postoperative nausea and vomiting in females undergoing thyroidectomy: a dose-ranging study. Anesth Analg 2000; 91: 1404-7.

9 Chernik DA, Gillings D, Laine $H$, et al. Validity and reliability of the Observer's Assessment of Alertness / Sedation Scale: study with intravenous midazolam. J Clin Psychopharmacol 1990; 10: 244-51.

10 Barton MD, Libonati M, Cohen PJ. The use of haloperidol for treatment of postoperative nausea and vomiting - a double-blind placebo-controlled trial. Anesthesiology 1975; 42: 508-12.

11 Rusch D, Eberhart L, Biedler A, Dethling J, Apfel CC. Prospective application of a simplified risk score to pre- 
vent postoperative nausea and vomiting. Can J Anesth 2005; 52: 478-84.

12 Lerman J. Study design in clinical research: sample size estimation and power analysis. Can J Anaesth 1996; 43: 184-91.

13 Tang J, Wang B, White PF, Watcha MF, Qi J, Wender $R H$. The effect of timing of ondansetron administration on its efficacy, cost-effectiveness, and cost-benefit as a prophylactic antiemetic in the ambulatory setting. Anesth Analg 1998; 86: 274-82.

14 Parlow JL, Costache J, Avery N, Turner K. Single-dose haloperidol for the prophylaxis of postoperative nausea and vomiting after intrathecal morphine. Anesth Analg 2004; 98: 1072-6.

15 Aouad MT, Siddik-Sayyid SM, Taha SR, et al. Haloperidol vs. ondansetron for the prevention of postoperative nausea and vomiting following gynaecological surgery. Eur J Anaesthesiol 2007; 24: 171-8.

16 Henzi I, Sonderegger J, Tramer MR. Efficacy, dose-response, and adverse effects of droperidol for prevention of postoperative nausea and vomiting. Can J Anesth 2000; 47: 537-51.

17 Gan T, Meyer T, Apfel CQ, et al.; Department of Anesthesiology, Duke University Medical Center.

Consensus guidelines for managing postoperative nausea and vomiting. Anesth Analg 2003; 97: 62-71.

18 Apfel CC, Kranke P, Katz MH, et al. Volatile anaesthetics may be the main cause of early but not delayed postoperative vomiting: a randomized controlled trial of factorial design. Br J Anaesth 2002; 88: 659-68.

19 Perrault LP, Denault AY, Carrier M, Cartier R, Belisle $S$. Torsades de pointes secondary to intravenous haloperidol after coronary bypass grafting surgery. Can J Anesth 2000; 47: 251-4.

20 Sharma ND, Rosman HS, Padhi ID, Tisdale JE.

Torsades de pointes associated with intravenous haloperidol in critically ill patients. Am J Cardiol 1998; 81: 238-40.

21 Benedict CR, Arbogast R, Martin L, Patton L, Morrill $B$, Habne $W$. Single-blind study of the effects of intravenous dolasetron mesylate versus ondansetron on electrocardiographic parameters in normal volunteers. J Cardiovasc Pharmacol 1996; 28: 53-9.

22 Kasinath NS, Malak O, Tetzlaff J. Atrial fibrillation after ondansetron for the prevention and treatment of postoperative nausea and vomiting: a case report. Can J Anesth 2003; 50: 229-31.

23 Baguley WA, Hay WT, Mackie KP, Cheney FW, Cullen $B F$. Cardiac dysrhythmias associated with the intravenous administration of ondansetron and metoclopramide. Anesth Analg 1997; 84: 1380-1.

24 Charbit B, Albaladejo P, Funck-Brentano C, Legrand $M$, Samain E, Marty J. Prolongation of QTc interval after postoperative nausea and vomiting treatment by droperidol or ondansetron. Anesthesiology 2005; 102: 1094-100.

25 White PF, Watcha MF. Are new drugs cost-effective for patients undergoing ambulatory surgery? Anesthesiology 1993; 78: 2-5. 